\title{
A itinerância das ideias e o pensamento social africano
}

Leila Maria Gonçalves Leite Hernandez*

Resumo: Este artigo tem como proposta central rechaçar a ideia de que a África é mero entreposto de artefatos culturais derivado de modelos e categorias ocidentais de análise. Ao partilhar as propostas teóricas próprias da abordagem pós-colonial sugiro recolocar esta problemática, identificando em que lugares e momentos as teorias e ideias políticas foram produzidas, como e onde foram lidas e reinterpretadas pelos intelectuais africanos e os limites de suas transformações. Nesta chave analítica, as formas africanas das narrativas construíram-se como fruto de "apropriação criativa" em contextos plurais e com temporalidades heterogêneas, o que possibilitou a criação de novos espaços para a imaginação política e para a imaginação histórica, desenhando a estrutura discursiva de um pensamento social africano centrado nas diversas acepções de unidade, cultura e identidade.

Palavras-chave: Pensamento social africano. "Apropriação criativa". Imaginação política. Imaginação histórica.

"[...] A critica nos diz. que devemos aprender a dissolver os idolos:
aprender a dissolvê-los dentro de nós mesmos. Temos de aprender
a ser ar, sonho em liberdade". (PAZ, 1984, p. 261).

* Professora livre-docente de História da África do Departamento de História da Faculdade de Filosofia, Letras e Ciências Humanas da Universidade de São Paulo. Doutora em Ciências Sociais pela PUCSP. E-mail: leila.h@uol.com.br

Anos 90, Porto Alegre, v. 21, n. 40, p. 195-225, dez. 2014 


\section{Introdução}

Parafraseando Octavio Paz (1984, p. 195), acredito que “[...] o africano não é uma essência, mas sim uma história [...]" e, não fosse outra, esta é uma forte razão para compreender o presente com um olhar voltado para o tempo passado, perscrutando as persistências que emprestam o fôlego necessário para se reinventar.

Diretamente ligado às circunstâncias históricas reais, o colonial vive em um universo de sentimentos, desejos, imagens, sofrimentos, medos, impulsos e frustações mal sepultados, frutos da experiência humana que tomam a forma de ideias, pensamentos e teorias. Como passado e presente moldam-se mutuamente, persistem as sombras do colonial, o terror das guerras de libertação e os desencantos trazidos pelo balanço das primeiras décadas dos Estados independentes e dos nacionalismos, por vezes, transmutados em políticas étnicas derivadas da construção de identidades com seu

[...] quinhão de pressupostos falsos erros e imprecisões que a cortesia chama de 'mito', a religião, de 'heresia' e a ciência de 'magia'. Histórias inventadas, biologias inventadas e afinidades culturais inventadas vêm junto com toda a identidade; cada qual é uma espécie de papel que tem que ser roteirizado, estruturado por convenções de narrativa a que o mundo jamais consegue conformar-se realmente. (APPIAH, 1997, p. 243).

Desafiados, os intelectuais, sobretudo os das gerações dos anos de 1960 e subsequentes, têm perguntado sobre seu papel na vida política e as possibilidades de intervir, atravessando uma longa fase reflexiva em que predominou a preocupação com o mito das singularidades, o significado do colonial e de sua interdependência com os modelos e as categorias ocidentais de análise. Colocam-se o desafio de identificar o colonial e o pós-independência como construções históricas, colocando em dúvida narrativas, fontes materiais, bases teóricas e a posição de sujeito dos historiadores confrontados com a visão ocidental de progresso, por meio da qual os países d'África (e também d'Ásia e d'América Latina) enquanto nações e estados são avaliados como verdadeiros fracassos.

Anos 90, Porto Alegre, v. 21, n. 40, p. 195-225, dez. 2014 
Partilho as propostas teóricas próprias da abordagem pós-colonial, que considera o colonial como um passado que vive e teima em cutucar as feridas da violência, provocando rupturas nas categorias de conhecimento, em particular, na produção discursiva niveladora de experiências pluri e hetero culturais do colonial. Nesta chave, cabe perguntar em que lugares e momentos as teorias e ideias políticas foram produzidas, como e onde foram lidas e reinterpretadas e os limites de suas transformações, marcando suas narrativas como "processos de afiliação", isto é, de "apropriação criativa" em contextos plurais (SAID, 2005).

No cenário da África dos vinte últimos anos do século XIX até as independências dos anos de 1960, as ideologias viajaram como partes de um intrincado processo itinerante de ideias e teorias políticas ocidentais (eurocêntricas) que dominaram o pensamento de toda uma época, transformando diferentes formas discursivas sobre o passado em ortodoxias sobre temas como cultura, civilização, raça, língua, nacionalismo e unidade cultural. Pouco a pouco, formulações comprometidas com a desconstrução dos paradigmas coloniais - não coesos, isto é, colonialistas em diferentes formas e graus - fundados em diversas leituras, em particular, na dialética do senhor e do escravo presentes em Phénomenologie de L'éspirit, de Hegel (1939) ${ }^{1}$; Manuscritos Econômico - Filosóficos de agosto de 1844, de Marx (2004); Manifesto Comunista, de Marx e Engels (1968); Imperialismo, fase superior do capitalismo e O Estado e a Revolução, de Lenin (1987); História e Consciência de Classe, de György Lukács (2003); e A noção de situação colonial, de Georges Balandier (1963), transformaram-se em críticas contundentes à situação colonial ${ }^{2}$ e ao racismo, ganhando lugar em diferentes contextos com temporalidades heterogêneas. As ideias das elites intelectuais africanas refizeram-se de forma plural, desvelando tensões e ambivalências, paradoxos e contradições do paradigma imperial britânico, francês, belga e português, em processos que iniciados em 1945 foram se acentuando com o número crescente de Estados politicamente descolonizados na África, em particular até meados dos anos de 1960, incluindo a fundação, em 1963, da Organização da Unidade Africana.

Exemplos significativos deste pensamento plural fizeram-se presentes em três obras que se tornaram clássicos nos debates anticolonialistas e antirracistas: Nations Nègres et Culture, de Cheikh

Anos 90, Porto Alegre, v. 21, n. 40, p. 195-225, dez. 2014 
Anta Diop (1954), Discurso sobre o colonialismo, de Aimé Césaire (1956) e A filosofia bantu, de Placide Temples (1955). Também estiveram presentes em artigos de intelectuais africanistas (africanos, afro-americanos e europeus) de grande envergadura, publicados entre 1956 e 1965, na revista Présence Africaine. Cito: o malgaxe Jacques Rabemananjara (1956), o psiquiatra martiniquenho Frantz Fanon (1956), o historiador afro-americano Horace Mann Bond (1956), Aimé Césaire (1956), Joseph Ki-Zerbo (1957), o afro-americano e liberiano por adoção W. E. Du Bois (1957), os senegaleses L. S. Senghor (1956), Mamadou Dia (1959), Alioune Diop (1959) e Cheikh Anta Diop (1959), o nigeriano Benjamin Nnamdi Azikiwe (1959), o historiador africanista britânico Basil Davidson (1961), o tunisiano Guy de Bossechère (1961), o tanzaniano Julius Nyerere (1961) e o político e antropólogo angolano Mário Pinto de Andrade (1962). ${ }^{3}$

A lista é extensa no que se refere aos intelectuais como às proposições deste debate e para os fins deste artigo não salientarei a importância de cada uma. As considerações teóricas e metodológicas serão tratadas tendo como foco duas circunstâncias históricas distintas, definidas pela situação internacional e pelo ambiente social e político local. A primeira refere-se à imaginação sobre a África, o Caribe (Antilhas) e EUA como terras de negros, sob a dominação colonial europeia ou sob as relações de dominação e segregação vividas em decorrência de terem sido homens escravizados. Tento apreendê-la valendo-me dos cenários de ideias políticas e culturais (no amplo sentido do termo) que condicionaram a trajetória do professor, diplomata, escritor e etnógrafo haitiano Jean Price-Mars (1876-1969).

A segunda circunstância histórica refere-se aos anos de 1950 e 1960, quando a retórica sobre a negritude e o pan-africanismo em torno da raça, das línguas e tradições culturais africanas cederam lugar à questão da luta pela independência. Foi quando líderes como o martiniquenho Franz Fanon e o "guineense cabo-verdiano" Amílcar Cabral atuaram em relação a uma geografia africana por essência, que continha a Argélia, a Guiné e Cabo Verde como espaços de guerras de libertação. Foi também quando a imaginação histórica e a teoria política deram concretude à efetiva possibilidade do pensamento social africano não ser colonizado de forma perene, assumindo feições próprias.

Anos 90, Porto Alegre, v. 21, n. 40, p. 195-225, dez. 2014 


\section{Pan-africanismo e nacionalismo cultural}

Retomemos três temas: a raça, a cultura e a nação. Os saberes construídos sobre as identidades que compuseram a estrutura discursiva do colonial tiveram sua gênese nas discussões germanistas conhecida como "querela das duas raças", que tomou corpo na virada do século XVII para o XVIII. Foi o início de um processo no qual a noção de raça foi ocupando o centro de um corpo ideológico fundamental para a etnografia europeia da segunda metade do XIX, partindo do pressuposto que apenas os ocidentais - porque "mais aptos" e "mais capazes" - tinham legitimidade para conceber ideias universalistas, naturalizando a submissão dos seres "inferiores" dos mundos dominados da África (e da Ásia), uma vez reduzidos a subprodutos do racialismo europeu. Esse foi um amplo debate que teve como principais protagonistas os naturalistas Georges Bouffon (1749) e Georges Cuvier (1830), os biólogos evolucionistas Nott e Glidon (1857), Charles Darwin (1859) e Richard Burton (1864). ${ }^{4}$ As ideias racialistas entrelaçadas ao etnocentrismo da cultura ocidental se fizeram presentes no imaginário europeu e norte-americano na literatura colonial, em charges publicadas na Alemanha, Inglaterra, Portugal, França, Bélgica e, sobretudo, nas feiras coloniais e em exposições universais realizadas nas capitais dos impérios como Londres (1851), Paris (1889), Lisboa (1900), registrando-se em maior número entre 1878 e 1912 e se estendendo por todo o século XX. ${ }^{5}$

Essas ideias expostas em diversas chaves de análise tiveram como contrapontos iluministas como o apresentado pelo marquês de Condorcet, que na "Epître aux Nègres Esclaves" sublinhava a igualdade dos negros em relação aos brancos. Mas a naturalização do "culto à raça" continuou sendo dominante e Arthur de Gobineau (1816-1882) reconhecido como importante ideólogo do "culto à raça". Em sua obra Essai sur L'inégalité des races humaines (1858) ${ }^{6}$, reiterou a divisão da espécie humana em brancos, amarelos e negros como pertencentes a raças diferentes e desiguais, dotadas de caracteres permanentes, transmitidos hereditariamente. Esse determinismo biologista fazia parte do reconhecimento científico da escala das quatro variedades raciais elaborada pelos naturalistas - com especial destaque para o botânico sueco Carolus Linnaeus, "pai da taxonomia

Anos 90, Porto Alegre, v. 21, n. 40, p. 195-225, dez. 2014 
moderna" - na qual eram articulados patrimônio genético, aptidões intelectuais e inclinações morais. Foi no âmbito desta perspectiva que se propôs compreender as agitações da modernidade, buscando a revolução haitiana como exemplo histórico da inaptidão da variedade negra, isto é, das tribos asselvajadas, cujo instinto de violência e desenfreada anarquia na luta pela independência, levou grande número de brancos à morte.

Tragédia, epopeia ou anarquia gerada por instintos, fato é que esta como outra rebelião escrava era predominantemente descrita utilizando-se métodos reducionistas, processos de descaracterização, modos de inventariar o diferente, o "outro", o não europeu - sobretudo africano - a partir da repetitiva hierarquização por critérios biologistas articulados a características morais e intelectuais.

O locus matricial deste dogmatismo sobre as diferenças entre os seres humanos viajou pelas capitais dos impérios europeus e também para as Américas aportando no Haiti, onde a resposta do antropólogo e jornalista Anténor de Firmin (1850-1911) à desigualdade das raças foi muito além de considerações de ordem biologista como principal elemento definidor da relação fortemente assimétrica entre colonizador e colonizado. Firmin - assim como outros intelectuais haitianos - em sua obra Essai sur l'égalité des races bumaines (alusão direta à obra de Gobineau), considerava a independência do seu país como resposta da raça negra, a "porta-bandeira da causa da igualdade". Uma igualdade para além da racial, econômica, social e política nos planos local e transnacional. Cito:

[...] essa independência mudou o regime econômico e moral de todas as potências europeias detentoras de colônias e a sua realização pesou também sobre a economia interior de todas as nações americanas que mantém o sistema da escravatura (FIRMIN, 1885, p. 61-62).

Este caráter épico da revolução haitiana estendeu-se por algumas décadas, como ficou registrado na obra do trinitino Cyril James. Em seu The Black Jacobins. Toussaint L'Overture and the San Domingo Revolution, cuja primeira edição foi de 1938, o ativista político ligado ao Independent Labour Party, da Inglaterra, e à IV Internacional, dirigida por Leon

Anos 90, Porto Alegre, v. 21, n. 40, p. 195-225, dez. 2014 
Trotsky, derramou seu grande entusiasmo pela rebelião escrava de São Domingos, que se esparramou para o Haiti, durando de 1791 a 1804, quando foi oficialmente decretada a independência do Haiti. ${ }^{7}$

Outra afirmação incisiva assemelhada à de Firmin foi de Jean Price-Mars (1876-1969), que teve como um dos seus grandes interesses o ofício de etnógrafo, detendo-se nas bases históricas das manifestações culturais do Haiti, em plena conjuntura de crise econômica, social e política, que gerou sucessivos movimentos de contestação usados como justificativa para a invasão de fuzileiros navais e marinheiros norte-americanos em 1914. Em Ainsi parla l'oncle - publicado em 1928 -, livro inovador escrito em plena ocupação norte-americana (1915-1939), procurava elevar a autoestima dos haitianos por meio do desenvolvimento de um nacionalismo cultural. Ao deslocar o biologismo para o culturalismo, afirmava que os haitianos não eram "franceses de cor", antes, homens nascidos em circunstâncias históricas que lhes conferia a herança de uma memória mista, a de franceses e a de haitianos.

Sem dúvida Price-Mars afastou-se da formulação europeia sobre as diferenças entre as raças e acabou por apreciar as tensões inerentes à própria engrenagem da situação colonial particular do Haiti, onde a sociedade apresentava-se como dividida em franceses e indígenas. Ambos os grupos eram tomados como homogêneos e no caso dos negros haitianos isto trazia distorções como a de afastar as tradições que provinham das famílias reais daquelas procedentes de tradições aldeãs. Sobre os assimilados, Price tinha uma percepção bastante negativa, imputando-lhes a responsabilidade de interromper o florescimento da cultura do país tinha por negarem suas raízes culturais, adotando padrões da cultura europeia - em moldes franceses - como forma de ascender socialmente. Para Price-Mars, as elites de assimilados eram arrivistas definidas por seu "bovarismo coletivo", expressão presente em La vocation de l'élite (1919), com a qual definiu a identificação que tinham com os aspectos da cultura europeia recusando-se a reconhecer o legado africano.

Deve-se assinalar, ainda, como Price-Mars ressaltou o surgimento de uma cultura local, com a dominância do crioulo haitiano (kreyòl ayisyen), da religião vodu e das tradições orais. Subjacente a esta reflexão, Price compreendeu que esta era uma cultura localizada

Anos 90, Porto Alegre, v. 21, n. 40, p. 195-225, dez. 2014 
- e não exclusivamente local -, carecendo de um discurso coletivo que, em termos políticos, fosse capaz de se expandir internacionalmente, o que o levou a valorizar as explicações da Teoria da Diáspora Africana e do Pan-Africanismo de cariz cultural, acolhidos nos meios intelectuais, artísticos e políticos na Paris da década de 1920. Uma década de franca efervescência política em que a exploração e as crueldades sofridas pelos africanos foram colocadas em pauta, levadas pelo impacto de Batouala, de René Maran, e das publicações de André Gide, Retour Du Tchad (1925) e de Voyage au Congo (1927).

Também foi a década da fundação, em Paris, da União Inter-colonial, da Ligue Universelle pour la Défense de la Race Noir, do Comité de Défense de la Race Nègre e do I Congresso Anticolonialista, incorporando críticas à violência exercida pelos abusos da burocracia colonial e ao racismo, reforçadas pelas esperanças criadas pela Revolução Russa e pela expectativa que o "esforço de guerra" alargasse direitos e liberdades. Mas os desdobramentos da I Guerra Mundial só trouxeram desencanto e indignação para asiáticos e africanos. O princípio da nacionalidade incluso no nacionalismo wilsoniano inspirou uma política que se firmava no direito dos povos colonizados de disporem de si, apenas quando civilizados o suficiente para obterem sua independência política.

\section{Raça e identidade: música, literatura e política}

Contraponto essencial da queda dos impérios na Europa, as análises em torno da questão da identidade nucleada na noção de raça ganharam contornos próprios. Um dos marcos foram os questionamentos mais sistemáticos das principais categorias colonialistas de conhecimento, envolvendo os fenótipos que conformavam as noções de "tribo" e a noção de "tradição", próprias da Etnologia, cuja pressuposição central era uma visão estática da história colonial. Em contraponto, o empenho de Price-Mars para a fundação do Instituto de Etnologia, em 1941, no Haiti, deu lugar à faísca de um pensamento que procurava ser transgressor, como na outra margem do Atlântico ocorria com o desempenho das "escolas" de Ibadan, Ajayi, Dar ES Salam e do Instituto Francês da África Negra. Todas 
as instituições fundadas na década de 1940, nas quais trânsitos e interferências diversas enfatizavam a pluralidade de línguas e de tradições locais - em particular as orais - enfrentando o desafio de identificar a simbiose das memórias coletivas. A preocupação de fixar por escrito essas tradições dominadas pelas narrativas os fatos marcantes para cada comunidade étnica, além de certa preocupação incomum em dar um quadro cronológico aos acontecimentos ecoavam sinais de "africanização do pensamento". (BARRY, 2000).

Amparada pela trajetória de Price-Mars - mesmo com incertezas - pude captar a errância das ideias na diáspora, revelada por sua aproximação do movimento cosmopolita do Harlem Renaissance, espaço de onde emergiram uma pluralidade de manifestações culturais tecidas no âmbito de circunstâncias históricas reais. Foi lá que despontaram os múltiplos entrelaçamentos da literatura e da música dos negros da África, das Américas, e daqueles dispersos pelos cantos do mundo. O Harlem foi o espaço no qual surgiu uma cultura vanguardista com ritmos e sons como o jazz, os espirituals, os blues e os sorrow songs, como analisou, em 1936, Alain Locke em um de seus textos memoráveis, The New Negro: An Interpretation. ${ }^{8}$

Mas o Harlem renascido também foi símbolo de resistência e força para criar um centro de cultura em uma terra da qual os negros tinham sido brutalmente expulsos. A bem dizer, o Harlem foi palco de uma tensão singular que atraiu artistas e intelectuais como os pan-africanistas Du Bois (Black Revolution, 1935), Blyden (Christianity, Islam and Negro Race, 1887) e Garvey (A Estrela Preta, $\mathrm{s} / \mathrm{d})^{9}$ que encabeçaram a luta política pela recusa da submissão das práticas e leis de segregação racial, pela franca defesa da dignidade dos negros, pela reivindicação por igualdade e direitos civis e pelo projeto de retorno à África, que não se cingiu a uma África indiferenciada, antes, a uma escolha metafórica por Serra Leoa e, sobretudo, pela Libéria como centros irradiadores de uma ação que construiria, na prática, as propostas anticoloniais de modernização e emancipação.

$\mathrm{Na}$ realidade o Harlem representou uma geografia de base afetiva e efetiva em um momento em que o racismo, a segregação e a assimilação tiveram várias respostas, tanto por parte do movimento da Negritude como do Pan-Africanismo em suas várias vertentes. A questão da raça passou a ser articulada à forte - não

Anos 90, Porto Alegre, v. 21, n. 40, p. 195-225, dez. 2014 
raro intransigente - oposição ao colonialismo e ao imperialismo capitalista (sobretudo após a II Guerra Ítalo-Etíope quando a Etiópia caiu sob o jugo italiano) e a proclamação da resolução central do $\mathrm{V}$ Congresso Pan-Africano -, reiterada pelo Movement for Colonial Freedom - fundado no Reino Unido, em 1954, voltado para a defesa dos direitos civis -, coordenador de organizações como o Council for Freedom in Portugal and Colonies -, cujo principal papel era o de escolher linhas de ação para mobilizar e organizar os desorganizados.

Para ilustrar o curso dessas afiliações, prossigo retomando em largas passadas a trajetória de Price-Mars, no momento em que no plano das ideias ganharam força os princípios de se afastar do pensamento, das ideias, representações e imagens eurocêntricas, marcando sua aproximação de dois intelectuais de posições políticas opostas, Aimé Césaire, fundador dos cinco números da revista L'étudiant Noir e autor de Cahiers d'un Retour au Pays Natal (1 ${ }^{\mathrm{a}}$. ed. em 1939) escrito entre 1936 e 1930, e Léopold Sédar Senghor (1948), autor de uma noção de negritude que opunha "emoção negra" à "razão helênica", em "Orfeu Negro". ${ }^{10}$ O primeiro, próximo do Partido Comunista Francês, e, o segundo, preposto do Partido Socialista; sua participação nas discussões do Congresso de Artistas Negros, em 1956, para o qual foi eleito presidente por unanimidade; ${ }^{11}$ e sua colaboração para a revista Présence Africaine, importante meio de expressão de um movimento político que reuniu africanos, antilhanos e europeus, difundindo a África aos cenários culturais europeus e americanos, mesmo que os leitores se restringissem aos intelectuais, artistas e alguns ativistas engajados.

Desde o seu lançamento, em 1947, a revista revelou agudeza de olhar ao tornar pública a variedade das culturas pré-coloniais, sendo que alguns de seus principais artigos foram comunicações apresentadas no I Congresso de Artistas Negros, em 1956, ${ }^{12}$ e destacavam como essenciais a relevância das línguas locais e da recolha das tradições orais para traçar os contornos do que seria uma presença afro-negra na África e na Diáspora. Reitero que alguns artigos publicados na Présence Africaine de 1956 são dignos de nota. Cito: "The spirit of civilization or the laws of African negro culture", de Léopold Sédar Senghor; "The cultural contributions and prospects of Africa", de Cheikh Anta Diop; “Culture and colonization”, de Aimé Césaire. ${ }^{13}$ 
Présence Africaine também sofreu o fascínio da diferença como característica histórica exclusiva do complexo colonial em voga nos anos de 1960. Embora de relance, seus artigos permitem entrever contraposições entre as diversas teorias sobre o império e o jogo de interesses nas diferentes experiências do colonial. Atualmente, a releitura dos artigos da revista sob a abordagem dos Estudos Pós-coloniais permite ao mesmo tempo perceber como as generalizações encobrem as variações do problema político de negar a situação colonial e o racismo, além de compreender a coexistência das esferas da sociedade e da burocracia colonial em que por certo houve tensões, mas não necessariamente claras contradições.

Contudo, voltando à produção acerca desses temas na emblemática revista, é possível identificar um princípio provocador voltado para mudanças radicais. Revela o espírito da época, a "força tarefa" característica dos anos 1960 no cultivo da astúcia em uma luta política de oposição à situação colonial, com diferentes graus de radicalidade. As escrituras ganharam a força retórica da persuasão na pena de intelectuais comprometidos com a "mutação dos espíritos" como Ki-Zerbo, Aimé Césaire, Jean-Paul Sartre, André Gide, Albert Camus, George Padmore e Roger Bastide. A força centrífuga das décadas de 1940 e 1950, estendendo-se até os anos 1960, modificou o panorama político do continente africano. Até 1960, tornaram-se politicamente independentes 29 países, o que reforçava nas elites intelectuais africanas um sentimento de que era possível provocar rupturas dos laços com o colonial, revelando, por isso, o sentido nevrálgico de uma ambiência marcada por intercâmbios culturais enriquecidos por análises acerca de outras experiências, como a dos cubanos Fernando Ortiz e Nicolas Guillen para o movimento da negritude, salientando que raça e cultura pertenciam à vertente identitária que levava à garantia de uma igualdade efetiva.

A bem dizer, essas ideias foram marcantes para os frequentadores da Casa dos Estudantes do Império, de Lisboa - como Noémia de Souza (2001), Agostinho Neto (1985), Amílcar Cabral (1980; 1989) e Mário Pinto de Andrade $(1997)^{14}$ como expressou este intelectual angolano, talvez um dos maiores exemplos de como as ideias tiveram diferentes apropriações criativas, sobretudo desde 1954, com a fundação do Centro de Estudos Africanos, em Lisboa.

Anos 90, Porto Alegre, v. 21, n. 40, p. 195-225, dez. 2014 
Digamos que a diáspora criou espaços de reunião para a pluralidade de colônias dos impérios europeus, em que, rompendo a barreira da língua, a Negritude e o Pan-africanismo ganharam corpo. Ao mesmo tempo, reconheceu a importância da prática política revolucionária como condição para os africanos conquistarem liberdade e direitos civis.

\section{Situação colonial e alienação}

Esses temas circularam nas capitais europeias entre as futuras lideranças dos movimentos de independência na África, absorvendo também uma contribuição fundamental do pensamento de Blyden (1927), ${ }^{15}$ o sentimento de raça como base para elevar a África à pátria de todos os negros em solo africano, por meio da interconexão de valores e aspirações comuns, geradoras de um sentimento coletivo, essencial para pensar políticas autônomas. Este foi um dos caminhos.

No entanto, os temas também se espalharam em circuitos nos quais intelectuais e lideranças políticas mostraram que não havia nada de abstrato e meramente conceptual em suas ideias, uma vez que a situação colonial e a alienação não eram conceitos metafísicos, e sim empíricos, geográficos e históricos, instrumentos metamorfoseados em energia mobilizadora. Pode-se caracterizar esse processo plural, de método e expressão diferentes, como derivado da análise de problemas comuns às colônias e de sua incidência sobre as várias camadas de excluídos carentes de sustentação própria para o exercício da política, o que levou as lideranças africanas à decisão de superar suas posições ideológicas de diferentes matizes e reunir esforços em torno de ações comuns para conquistar as independências.

Esta estratégia teve lugar em espaços cosmopolitas em que representantes de países africanos e asiáticos reconheceram equivalências, homologias, ambiguidades e contradições, o que contribuiu para alargar a imaginação histórica. Mas, enquanto em 1954, na Conferência Governamental Afro-Asiática, buscava-se construir laços de solidariedade, tendo como eixo a condenação das políticas imperialistas definidas como "crimes contra a humanidade". Embora com sinais visíveis de sua natureza predominantemente retórica, a 
Conferência de Bandung ${ }^{16}$ levantou a bandeira do não alinhamento como moldura de dez princípios para a construção das soberanias externa e interna, enlaçando a equidade dos direitos humanos aos das nações. Estes pontos foram reiterados em outros fóruns internacionais, como a Organização das Nações Unidas, em 1960, com a aprovação da Declaração sobre a Concessão a Independência dos Países e Povos Coloniais e, em 1966, quando foi aprovado o Pacto sobre os Direitos Econômicos, Sociais e Culturais e o Pacto sobre os Direitos Civis e Políticos que proclamou o direito dos povos à autodeterminação.

Estes acontecimentos ensejaram deslocamentos reveladores das ligações entre as histórias e culturas das Américas, África e Europa e enfatizaram a censura das relações assimétricas de poder entre países ricos e países pobres do chamado Terceiro Mundo. E mais: ao destacar a importância das aspirações locais e as reivindicações dos territórios periféricos (incluindo os asiáticos e americanos), um conjunto de países criou um campo próprio de soberania dentro da sociedade colonial, promovendo esgarçamentos na universalidade ocidental.

A descolonização, posterior ao V Congresso Pan-africano e a II Guerra Mundial provocou os intelectuais à procura de novos de pontos de referência, o que possibilitou-lhes encontrar como fundamento um misto de raízes e caminhos que apontavam para uma pluralidade de vias nacionais para o socialismo dentro do socialismo, alargando o espaço das interpretações heterodoxas em detrimento das ortodoxias. Este foi o sentido das "apropriações criativas" que os principais intelectuais e lideranças africanas fizeram, sobretudo, das obras de Hegel (1939) e do jovem Marx (2004). De Marx e Engels (1968), de Lukács (2003), Balandier (1963), Sartre (1956) e, possivelmente, de Gramcsi (1930). ${ }^{17}$ Com certeza, as viagens transnacionais mostraram que, com distintas origens, experiências, temporalidades, imbricações culturais, além de diferentes - por vezes até opostas - posições políticas e ideológicas, a estrutura discursiva do pensamento sobre o complexo colonial esteve no centro de calorosos debates, conformando as tendências independentistas e assimilacionistas enquanto caminhos para a formação de estados e nações soberanos. Elas denotam afiliações plurais do pensamento marxiano em intelectuais como Cheik Anta Diop (1954), Senghor

Anos 90, Porto Alegre, v. 21, n. 40, p. 195-225, dez. 2014 
(1960), N’krumah (1965), Césaire (1977), Mário Pinto de Andrade (1999), Eduardo Mondlane (1995), Franz Fanon (1979), Amílcar Cabral (1980), e Aquino de Bragança (2014).

De certo modo, a trajetória e a apropriação criativa de ideias na conjuntura dos anos 1950 e 1960 são sugestivas para repor a pergunta: como a história penetra e estrutura o discurso político? Assinalo que é inegável o ganho que a negritude e o pan-africanismo tiveram enquanto movimentos identitários, em particular, com o approach da Antropologia dos anos de 1950 compromissada em enterrar a alcunha de "filha do imperialismo". Porém, as ideias e as teorias que constituem o pensamento social africano também são tributárias das afiliações múltiplas dos conhecimentos da Filosofia e da Teoria Política desenvolvidas na Europa, com suas ambivalências sobre o nacional e a cultura nacional, expressos pela palavra falada e pela palavra vivida.

Nesta chave explicativa, as escrituras de Franz Fanon (1979; 2009) e Amílcar Cabral (1980) encerram uma tentativa de alargar a compreensão de perspectivas pluralistas reinterpretados conforme as circunstâncias históricas e as escolhas dos caminhos para a independência. Foram de Frantz Fanon as mais inflamadas asserções sobre a dominação antinômica do homem negro, africano, colonizado pelo homem branco, europeu, colonizador. Estruturadas a partir dos conceitos de alienação e de situação colonial atestam suas fontes de origem, imprimindo inflexões e assertivas próprias.

A categoria de alienação presente nos textos de Fanon e especialmente tratada em Os Condenados da Terra - e mesmo que de forma menos clara e incisiva nos de Cabral - marca uma acentuada interpretação francesa do idealismo alemão, em particular, da Gênese e estrutura da fenomenologia de Hegel, e a Introducão à Leitura de Hegel, duas obras datadas de 1946, as quais propagam - ainda que de forma lenta - uma compreensão do sistema hegeliano com raízes na problemática da alienação, tornando clássica a dialética do senhor e do escravo nas discussões sobre a dominação social, econômica e cultural. Data do mesmo período o reconhecimento da importância dos Manuscritos de Paris, de Karl Marx (1844) traduzido para o francês cerca de 80 anos depois, em 1932. Nesses, Marx retomou o pensamento hegeliano sobre a alienação e o utilizou para 
compreender a luta de classes, fundamentando sua análise em um humanismo que passou a comandar as discussões da intelectualidade francesa. Embora em outra chave de análise, mas nesta ordem de ideias, a dimensão humana da libertação ganhou ênfase no âmbito de um debate entre marxismo e existencialismo realizado sob a marca do humanismo. Nesta perspectiva, em 1946, em um mundo ainda atônito com o final da II Guerra Mundial e com o genocídio dos judeus acrescido das crescentes fissuras do colonial, não é de espantar que O Existencialismo é um Humanismo, de Jean-Paul Sartre, tenha se tornado uma obra clássica. ${ }^{18}$ Não resta dúvida que este debate teve influências diretas em Franz Fanon, que passou a conceber a libertação nacional sob o signo da humanização universal do próprio homem.

Em 1951, Georges Balandier elaborou o conceito de situação colonial enquanto fenômeno social total, entrelaçando metrópole e colônia como duas partes de um mesmo processo histórico. Ao romper com as visões particularistas da Antropologia Anglo-Saxônica, propôs, de forma inédita, uma compreensão globalizante do contato entre civilizações, levando em consideração para além da face econômica do imperialismo, suas manifestações mais profundas formadoras da personalidade do homem colonizado, um homem definido pela alienação. (BALANDIER, 1993).

Cinco anos depois, Sartre reivindicou a autoria do conceito de situação colonial, porém os textos em que mais o utilizou tiveram nítidas marcas de um forte comprometimento com o ativismo político, tanto no combate aos racismos como aos colonialismos e aos imperialismos, como atestam os Prefácios para $O$ retrato do colonizado frente ao colonizador, de Albert Memmi (1967); Orfeu Negro, de Senghor (1948) e Os condenados da terra, de Franz Fanon (1961).

Não parece abusivo reiterar que a dialética hegeliana do senhor e do escravo e o conceito de situação colonial como fenômeno social total - redescoberto como instrumento teórico pelos Estudos Pós-Coloniais desde os últimos trinta anos do século passado - permearam as inúmeras discussões de intelectuais - sobretudo dos pesquisadores de Estudos Africanos e líderes políticos africanos - acerca das diferentes formas de dominação, dos racismos, dos colonialismos e das colonialidades, despindo a falsa dualidade dicotômica entre 
colonizadores e colonizados, europeus e africanos, brancos e negros. Pode parecer ousado afirmar, mas tudo leva a crer que Fanon compreendeu muito bem a historicidade da dialética, incorporando-a no seu projeto de superação das problemáticas racial e nacional, tratando-as por meio das categorias teóricas - da alienação e de complexo colonial - acentuadas por um tom de radicalidade politica ímpar, característica do autor.

Para além das categorias colonizador/colonizado, branco/ negro, opressor/oprimido perguntava: “quem somos nós?” e "por que estamos assim?”, na procura pelas raízes dos condicionalismos das situações de dominação particulares do colonial no contexto da Argélia. O olhar de Fanon sobre os processos históricos que levaram à revolução levou-o a concebê-la como uma luta pela liberdade nacional, para a conquista da própria terra e, em especial, uma forma de granjear dignidade humana. Por isso havia de ser reunida uma energia mobilizadora calcada em uma "tomada de consciência" - aliás, em consonância com as ideias de Sartre - da natureza e do sentido da violência presentes em todas as dimensões da vida social, para ter clareza do significado da autenticidade e dos engodos de uma libertação inautêntica. Com certa dose de maniqueísmo, para Fanon, [...] "Nas colônias a infraestrutura econômica é igualmente uma superestrutura. A causa é consequência: o indivíduo é rico porque é branco, é branco porque é rico.”. E explica:

É por isso que as análises marxistas devem ser ligeiramente distendidas cada vez que abordamos o problema colonial. Não há nem mesmo conceito de sociedade pré-capitalista, bem estudado por Marx, que não exigisse ser repensado aqui. (FANON, 1979, p. 29).

A notável força motriz que levava à revolução era "a violência atmosférica" entranhada na violência libertadora do colonizado, como resposta proporcional à exercida pelo opressor, transcendendo a condição do oprimido para se revelar como libertação do homem em geral. Significa dizer que a unidade do "povo negro" não era racial nem territorial, mas dos colonizados como um todo. Nesta ordem de ideias, Frantz Fanon (1979; 2009) e Aimé Césaire (1977) 
convergiam no realce conferido à nação como força aglutinadora do processo revolucionário radical, tendo à frente o campesinato como alternativa para a quase ausência do proletariado urbano e assimilado.

Essas ideias ecoaram fora das capitais dos impérios europeus sendo, nas palavras de Mário Pinto de Andrade, as que mais o impressionaram na sua juventude. É bastante plausível que tenha ocorrido algo semelhante com outras lideranças como Eduardo Mondlane (1995), Aquino de Bragança (2014), Viriato da Cruz (2013), Lucio Lara (2014), Agostinho Neto (1985) e Amílcar Cabral (1980). Este, mesmo sem o tom apaixonado de Fanon, considerava a urgência de romper a assimilação, o tribalismo e os valores "tradicionais" impeditivos do desenvolvimento de uma cultura popular, para que o movimento de libertação ganhasse eficácia, ideias que, no geral, foram compartilhadas e debatidas pelos jovens da Casa dos Estudantes do Império e do Centro de Estudos Africanos.

\section{A "violência atmosférica" e a "unidade e luta"}

Como vozes revolucionárias dos colonizados, Fanon e Cabral sublinharam a importância dos movimentos nacionalistas - e Fanon também dos movimentos negros - aos quais as lideranças políticas deveriam se vincular organicamente para a superação das várias interdições e crueldades entranhadas no complexo colonial. Ambos até certo ponto também concordavam que sem a "desalienação do próprio ser" e a "tomada de consciência" não seria factível chegar à verdade nacional. Neste registro, a dignidade era o exato contraponto da desigualdade imposta pela violência que regia as relações econômicas, os costumes, os valores e a fé religiosa, além de moldar a própria personalidade do homem colonizado com o barro da inferioridade e as tintas do ressentimento.

Pôr termo a um fenômeno social total significava, portanto, destruir sua integralidade, acabar com o processo duro e violento, inclusive da "violência atmosférica" com requintes patológicos característicos do drama colonial. A questão toda é compreender que falar do colonial é falar de violência e que violência significa confisco, preconceito, fome, humilhação, castigos corporais, formas 
compulsórias de trabalho, cerceamento das manifestações culturais, somada à violação da privacidade, da saúde, da educação e da habitação. Ora, creio não haver exagero em afirmar que extirpar a violência, muitas vezes, pode exigir o exercício de uma luta pela liberdade com uma forte carga de agressividade.

Penso, entretanto, que a violência quando exercida pelo colonizado foi subitamente alterada e subtraída do espaço ocupado em pelo menos um século de permanência do complexo colonial, transformada em lugar comum, reduzida ao despropósito do exercício violento da força física. Esta inversão ideológica tem um peso nada desprezível no discernimento empobrecido que naturaliza o sentido de uma colonização fundada pela negação da natureza humana. Não seria esta uma justa razão para tomar para si a violência - enquanto noção vazia de historicidade - não para "pôr termo à história da colonização", rompendo as condições vigentes a partir de suas raízes, pensando a libertação nacional em termos de humanização universal do próprio homem? (FANON, 1979).

Neste campo do pensamento crítico, a posição de Amílcar Cabral (1976, p. 160) de "[...] pensar com as nossas cabeças [...]" também se revelou interessante, remetendo-o a análises mais alargadas que compreendiam várias alterações da situação internacional: as independências de países asiáticos, em especial, da Índia e da Indonésia; a revolução chinesa; as independências do Egito - mesmo que discutível -, da Guiné-Conacri e de Gana; as crises e revoltas por liberdades nos países do bloco soviético. Estas turbulências atreladas ao ambiente social e local levaram a diferentes reações e análises. Transnacionais, as afiliações mais uma vez foram múltiplas, e as ideias sobre um mundo unitário, mas nada homogêneo, diversificaram-se, tornando-se possível e desafiadoramente cobiçado traçar estratégias políticas concretas nos vários países do "Terceiro Mundo". Talvez por isso, cerca de d uas décadas depois Mário Pinto de Andrade tenha reiterado a pergunta de Cabral: "[...] quem somos no desconcerto planetário e que futuro para esta humanidade?" (ANDRADE, 1989, p. 65). A pergunta revelou com clareza a referência à África, sobretudo, aos países sob a longa dominação de Portugal e, mais ainda, à Guiné e Cabo Verde. Daí a convocação imediata de Cabral na Conferência os Povos Africanos, em 1961, para que as lideranças 
construíssem uma aliança em torno da "união, da unidade e da vigilância” local, africana e afro-asiática. Não fugia desta direção a fundação da Frente Revolucionária Africana para a Independência Nacional (FRAIN) e da Conferência das Organizações Nacionalistas de Libertação das Colônias Portuguesas (CONCP), às quais cabia reunir "todas as organizações de massas e de todos os partidos políticos dos países africanos sob a dominação portuguesa", além de mobilizar e organizar as sociedades em torno das lutas em curso.

A esta tática propositiva no plano continental atrelavam-se a tática e a organização condicionadas pelas particularidades históricas de cada país. Para Cabral esta era uma tarefa bastante dificultada por sua posição de líder de um movimento que se transformou em um só partido à frente de processos históricos bastante diferenciados com especificidades próprias de Cabo Verde e Guiné. Em outras palavras, tratava-se de unir em uma mesma guerra de libertação sob o comando do Partido Africano para a Independência da Guiné e de Cabo Verde (PAIGC), dois países com diferentes graus de heterogeneidade: economias distintas, sociedades e estruturas de poder diferentes e culturas (línguas, valores, costumes, símbolos e religiões) heterogêneas, desde o período anterior ao século XV.

Acrescente-se que os processos colonizatórios não tinham nem comportavam um mesmo sentido, tornando Cabo Verde e Guiné duas colônias classificadas e hierarquizadas pela metrópole portuguesa a partir da homogeneidade ou heterogeneidade de suas populações, característica decisiva para garantir ou dificultar significativamente o projeto de assimilação de um mundo que orgulhosamente " $O$ português criou". ${ }^{19}$ Entretanto, mesmo com os cargos de segundo e terceiro escalões da burocracia colonial na Guiné ser preenchidos por cabo-verdianos, gerando um jogo de intensas contraposições, a necessidade de unir era imprescindível, sendo um desafio que precedia os demais. A situação tornou-se ainda mais crítica porque as sociedades não apresentavam equivalências quanto à situação revolucionária.

Pela simples razão de que interpretar o mundo não implica necessariamente mudá-lo, as diferentes circunstâncias socioculturais ganharam peso ainda maior. Estava posta a necessidade (que ainda perdura) de compreender o marxismo como fenômeno histórico em processo de constante diversificação. Este era um pressuposto

Anos 90, Porto Alegre, v. 21, n. 40, p. 195-225, dez. 2014 
que dominava o pensamento de Cabral, como atesta o discurso feito em 1966, em Havana, na Conferência Tricontinental. Nesta ocasião afirmou que na África - talvez menos ainda em Cabo Verde e na Guiné - não haveria uma revolução do proletariado, dada a sua inexistência. Para ele, no caso específico do PAIGC, mesmo com uma boa dose de incerteza, caberia à pequena burguesia, sabidamente ambígua e ambivalente, tomar a dianteira do movimento de libertação, tendo os camponeses como força social de apoio, daí a necessidade de seu suicídio político no pós-independência. Este processo de luta estaria grávido da nação, uma nação fruto da unidade construída com a pluralidade de grupos étnicos, além das várias divisões criadas pelo colonizador como entre indígenas e assimilados, gente da cidade e gente do campo, gente de Cabo Verde e gente da Guiné. Por circunstâncias que a história colocou à teoria, a escolha de Cabral não foi a mesma de Fanon. $\mathrm{Na}$ Argélia dos anos de 1950, os camponeses foram identificados como a "verdadeira força da revolução".

São questões que levam a mais dois temas controversos, o da cultura e o da nação na África. Mesmo de forma sabidamente lacunar, é oportuno retomar Fanon e Cabral, para os quais a cultura nacional é um tema necessário para compreender a noção de nação, porquanto é um campo privilegiado da luta política. Por isso ainda que por caminhos e formas próprias - ambos assinalaram a premência da tomada de consciência do caráter alienador da cultura dominante do europeu, branco, colonizador, para que se criassem projetos - no sentido sartreano do termo - de propor uma cultura nacional futura, no âmbito dos processos de libertação, nos quais nascia o Estado e se buscava construir a nação.

Para Fanon, a reafirmação da cultura negro-africana seria possível desde que passasse "primeiramente pelo apoio incondicional à luta de libertação dos povos" (FANON, 1979). Sagaz, também não descurou das ideias centrais do líder Ferhat Abbas contidas no Manifesto do Povo Argelino, em que se definia que a cultura para a independência deveria ser erguida a partir de três princípios interligados: a Argélia como pátria, o islamismo como religião e o árabe como língua. Só esta cultura conferiria legitimidade à nação, garantindo uma nova dimensão na existência do homem argelino. 
Cabral, por sua vez, afastou-se da ideia de uma "cultura racial ou continental", observando que, como a história, as culturas desenvolviam-se desigualmente no âmbito continental, racial ou de uma determinada sociedade. Sobretudo tendo pela frente uma geografia cultural especialmente heterogênea relativa às diferenças regionais das ilhas de Cabo Verde e - onde residia a dificuldade maior - a complexidade cultural dos povos da Guiné (como balantas, manjacos, fulas, mandingas e papéis), construir uma cultura nacional pressupunha que antes se estabelecesse uma resistência cultural, a mais eficiente das resistências, fortalecida por elementos comuns que teriam sobrevivido de vez que a repressão não tivera condições de eficácia e efetividade, dadas as próprias fissuras do colonial. Cito Cabral:

[...] nem nas classes dominantes autóctones (chefes tradicionais, famílias nobres, autoridades religiosas) se produz, em geral, uma destruição ou depreciação importante da cultura e das tradições. Reprimida, perseguida, humilhada, traída por certas categorias sociais comprometidas com o estrangeiro, refugiada nos povoados, nos bosques e no espírito das vítimas da dominação, a cultura sobrevive a todas as tempestades para depois, graças às lutas e libertação, recuperar todo o seu poder de florescimento. (CABRAL, 1976, p. 14-15).

Há fortes indícios de que Fanon (1979) concordaria sem restrições com a definição de Cabral (1978) acerca do papel da cultura nacional para o êxito da luta de libertação, uma vez que para ambos a cultura representava a realidade histórica concreta dos dominados. Em discurso proferido em 1970, na Universidade de Syracuse, Cabral observou que a cultura era ao mesmo tempo fruto e condicionante da história de "um povo", característica que se não fosse respeitada poderia redundar na grande falha de um movimento de libertação. (CABRAL, 1970).

Por estas razões, a nação africana enquanto fruto da unidade tecida na diversidade seria gestada em uma luta cujo principal objetivo era promover a ruptura do modo de produção colonial e buscar a recuperação do controle das forças produtivas pela via revolucionária, para que fossem construídos os pilares de um crescimento

Anos 90, Porto Alegre, v. 21, n. 40, p. 195-225, dez. 2014 
autônomo. Significa que a libertação deveria ir muito além da revolução nacional e da independência política, completada por um processo de revolução social. Está claro que a tarefa de organizar os desorganizados era decisiva: como conduzi-la?

Como seria de esperar este embate, segundo o projeto de Cabral - e também o de Fanon - incluía a resistência, a descolonização e a libertação irromperia com a mobilização das massas, para a qual sua prática como agrônomo lhe deu o necessário embasamento. $\mathrm{O}$ Recenseamento Agrícola elaborado por Cabral, em 1953, possibilitou seu conhecimento de dezoito comunidades étnicas e da área cultivada por cada uma delas e onde eram desenvolvidas suas atividades agrícolas em torno das quais se estruturava a vida cotidiana. Foi nesse contato que Cabral identificou que eram os anseios e as reivindicações das massas, na maioria formada por camponeses, e não as ideias das lideranças, as características propulsoras da luta em torno de uma "real melhoria das condições de vida". Nestas circunstâncias históricas, emergiu a principal bandeira de luta do movimento: "Pão, Terra e Liberdade", três condições fundamentais para mobilizar e organizar as massas para construir uma nação com "paz e progresso". (CABRAL, 1974).

\section{Considerações finais}

Da resistência ao confronto, desde as últimas décadas do século XIX até as independências africanas, vários processos históricos na África, América e Europa desafiaram as elites intelectuais africanas. Os questionamentos acerca da estrutura discursiva ocidental foram diversos e as escrituras heterogêneas em relação à teoria e à prática política anticolonial voltadas para enfrentar o paradigma da razoabilidade das diferenças que naturalizam as desigualdades, justificando as várias formas e os diferentes graus de violência, e os racismos, sobretudo, em relação aos negros.

As respostas culturais foram variadas e se transformaram, condicionadas pelas diferentes conjunturas históricas das resistências e conexões assimétricas que pontuaram o enraizamento das práticas administrativas coloniais nos países africanos, em especial, entre 1870

Anos 90, Porto Alegre, v. 21, n. 40, p. 195-225, dez. 2014 
e 1914, no período entre guerras, a indignada mobilização contra a invasão da Etiópia pelo exército de Mussolini, em 1936, e a II Guerra Mundial, com a Alemanha nazista perpetrando o genocídio de judeus. De modo desconcertante, as contradições puseram os impérios europeus em cheque, desnudando racismos e etnocentrismos. A civilização ocidental enredava-se em suas mazelas, o império foi posto em cheque e a resistência africana sofreu transformações variadas, respondendo à heterogeneidade dos povos na África.

Transnacional, o pensamento africano enriqueceu-se entrelaçando trajetórias individuais em trajetórias reveladoras de constantes transformações "no espírito e na imaginação" na conhecida expressão de Basil Davidson. À apropriação crítica do rico caldo da resistência cultural do Harlem Renassaince entrelaçaram-se os primeiros esgarçamentos da Antropologia colonial fortalecidos pelas contribuições do pan-africanismo de Du Bois, Blyden e Garvey registradas nas comunicações do I Congresso de Artistas Negros, em 1956. Ao retomar um pouco dos caminhos de Price-Mars, revelam-se como africanos e europeus tinham os mesmos terrenos de luta e quanto foi proveitosa a itinerância das ideias.

Ao ter como centro as independências, foram construídos uma pluralidade de caminhos em resposta às necessidades, aos anseios, às inquietações e aos sonhos dos diferentes povos africanos, deixando à mostra outro processo de "apropriação criativa" desta feita, de obras de Marx, Lênin, Lukács e Balandier. A totalidade da situação colonial desafiava respostas de maior radicalização política, carecendo de ideias e práticas políticas capazes de romper a integralidade da alienação.

A convergência entre a luta de classes - definida de forma heterodoxa - e as lutas nacionais aproximou Cabral, no plano da teoria, da "consciência conciliada" da qual Lukács abdicou, ainda que se mostrasse alerta para contornar as armadilhas da alienação. (SAID, 2005, p. 32). Esta opção, com claras influências da III Internacional, respondia a linha política marcada pela organização de uma frente única de libertação nacional. Estas ideias estiveram em absoluta consonância com a radicalização, em particular, como atestam as obras de Fanon e de Cabral. Para o primeiro, tratava-se de combater o colonial desde as suas raízes com o grau de violência ao quais os colonizados foram submetidos.

Anos 90, Porto Alegre, v. 21, n. 40, p. 195-225, dez. 2014 
Já a prática política de Cabral, ele próprio um líder à frente de uma guerra de guerrilha que se desenrolava combinando treino militar e formação política, tendo como exemplo a tática e a estratégia do vietnamita Vo Nguyen Giap. Cabral era um homem de ideias, respeitado nos fóruns internacionais onde tecia alianças a favor da independência, em particular, das colônias portuguesas. Mas foi, sobretudo, um líder guerrilheiro com os pés fincados no chão da Guiné, conduzindo uma nação em armas.

Não me afasto do constante movimento das ideias sem desdobrar uma ponderação sobre o fato de que ao voarem elas desembarcam em territórios geograficamente dispersos, usando a linguagem europeia e quase sempre a língua do colonizador. Entretanto, os intelectuais e líderes políticos africanos conservaram o olhar atento às questões que a história colocava à teoria, criando novas conotações aos temas tratados pelo olhar da Filosofia, da Teoria Política e da Antropologia, com os quais embasaram um pensamento social africano em contínuo processo de construção, "[...] com a imaginação curada da fantasia e decidida a enfrentar a realidade do mundo." (PAZ, 1984, p. 261).

\section{THE TRAVELLING IDEAS AND THE SOCIAL AFRICAN THOUGHT}

Abstract: The central proposal of this article is to reject the idea that Africa is a mere warehouse of cultural artifacts derived from Western models and categories of analysis. By sharing the theoretical proposals of the postcolonial approach itself, I suggest reestablishing this issue, by identifying places and moments in which the theories and political ideas were produced, how and where they were read and reinterpreted by African intellectuals and the limits of their transformations. In this analytical key African narrative forms were constructed as a result of "creative appropriation" in plural contexts and heterogeneous temporalities, which enabled the creation of new spaces for political imagination and the historical imagination, drawing the discursive structure of a African social thought centered on the various meanings of unity, culture and identity.

Keywords: African social thought. "Creative appropriation". Political imagination. Historical imagination. 


\section{Leila Maria Gonçalves Leite Hernandez}

\section{Notas}

${ }^{1}$ Hegel (1939). No Prefácio encontra-se a dialética do senhor e do escravo que é retomada até os dias de hoje para as discussões sobre as diversas formas de dominação (econômica, social e política) e da alienação.

${ }^{2}$ Marx (2004): Manuscritos Filosóficos de Agosto de 1844 ou Manuscritos de Paris, cujo primeiro manuscrito é sobre o trabalho alienado. Há uma versão em português editada pela Boitempo; Marx e Engels (1968): Manifesto Comunista, São Paulo; Ed. Escriba, 2. ed.; Lenin (1987): O Estado e a Revolução e Imperialismo, fase superior do capitalismo, sobretudo, os seguintes capítulos: "A partilha do mundo entre as grandes potências"; "O imperialismo, fase particular do capitalismo"; e "A crítica do imperialismo e o lugar do imperialismo na História". Ambos os livros podem ser encontrados em The Marxists Internet Archive; História e Consciência de Classe, de Lukács (2003); e Georges Balandier (1963): A noção de situação colonial; Lukács (2003): História e Consciência de Classe, Estudos sobre a dialética marxista. São Paulo: Martins Fontes, em que o autor trata das condições e possibilidades de articulação entre teoria e prática; Balandier (1963): "A noção de situação colonial" é o $1^{\circ}$ Capítulo de Sociologia Actuelle de l'Afrique Noire. Dynamique des changement sociaux em Afrique Centrale, Paris: Press Universitaires de France. A primeira edição é de 1955.

${ }^{3}$ Nations Nègres et Culture, de Cheikh Anta Diop (1954), Discurso sobre o colonialismo, de Aimé Césaire (1956) e A filosofia bantu, de Placide Temples (1955). Também estiveram presentes em artigos de intelectuais africanistas (africanos, afro-americanos e europeus) de grande envergadura, publicados entre 1956 e 1965, na revista Présence Africaine. Cito: o malgaxe Jacques Rabemananjara (1956); o psiquiatra martiniquenho Frantz Fanon (1956); o historiador afro-americano Horace Mann Bond (1956); Aimé Césaire (1956); Joseph Ki-Zerbo (1957); o afro-americano e liberiano por adoção W. E. Du Bois (1957); os senegaleses L. S. Senghor (1956), Mamadou Dia (1959), Alioune Diop (1959) e Cheikh Anta Diop (1959); o nigeriano Benjamin Nnamdi Azikiwe (1959); o historiador africanista britânico Basil Davidson (1961); o tunisiano Guy de Bossechère (1961); o tanzaniano Julius Nyerere (1961); e o político e antropólogo angolano Mário Pinto de Andrade (1962)

${ }^{4}$ Exemplos significativos deste pensamento plural fizeram-se presentes nas escrituras de: Jacques Rabemananjara ("Europe and ourselves"), L. S. Senghor ("The spirit of civilization or the laws of African Negro culture"), Frantz Fanon ("Racism and culture"), Horace Mann Bond ("Reflections comparative on West 


\section{A itinerância das ideias e o pensamento social africano}

African Nationalist movements"), Cheikh Anta Diop ("The cultural contributions and prospects of Africa") e de Aimé Césaire ("Culture and colonisation"), todas publicadas na Revista Présence Africaine, no ano de 1956. E nos anos subsequentes cito em 1957: Joseph Ki-Zerbo ("L'histoire recommence”); W. E. Du Bois ("La foi des ancêtres"). Na Présence Africaine, n. 24-25, Feb.-May 1959, destaco: "The ming of this Congress", de Alioune Diop; "African cultural unity", de Cheikh Anta Diop; "The foundation of our unity arising from the colonial epoch", de J. Rabemananjara; "The reciprocal basis of national cultures and the struggles for liberation", de Frantz Fanon; "Proposition pour l'Afrique", de Mamadou Dia; e "Nigeria in world politics", de Nnamdi Azikiwe. Na Présence Africaine, n. 39; quarto trimestre, 1961: "Angola", de Basil Davidson; "L'unité africaine”, de Guy de Bossechère; Na Présence Africaine, n. 41 v. 13, second quarterly, 1962 saliento: "Political and cultural solidarity in Africa", de Alioune Diop; "Literature and nationalism in Angola”, de Mario de Andrade. Por fim, na Présence Africaine, n. 53 v. 25, first quarterly, 1965 ressalto: "The negro-african personality", de Joseph Ki-Zerbo. E neste mesmo número da revista, de 1965, cito: "Notes on decolonization" de Alain Albert. Vale salientar que todos os exemplares citados podem ser consultados na Biblioteca Florestan Fernandes, FFLCH/USP.

${ }^{5}$ LECLER, Georges-Louis, Conde de Bouffon. Histoire Naturelle Génerale e Particuliere, avec la Description du Gabinet du Roy. Paris: Imprimerie Royale, 1749; CUVIER, Jean Leopold Nicolas Frédéric. Discours sur les revolutions de la surface du Globe, [S.I.: s/n], 1830; NOTT, Josiah Clark; GLIDON, George. Raças indígenas da terra, 1857; BURTON, Richard. "Notes". In: Anthropological Review, v. II, 1864. DARWIN, Charles. The Origin of Species by meems of natural selection or the Preservation of favored raced in the struggle for life. London: John Murray, Albemarle Street, 1859; BURTON, Richard Francis. Notes on scalping. Anthropological Review, 1864. Todas as obras citadas são alvo de analise em SCHWARCZ, Lilia Moritz. O espetáculo das raças: cientistas, instituições e questão racial no Brasil - 1870-1930. São Paulo: Cia das Letras, 1993. A exceção é a obra de Richard Burton analisada por GEBARA, Alexsander. A África de Richard Francis Burton, Antropologia, política e livre-comércio. São Paulo: Alameda, 2010. Ainda sobre as questões do racismo e do etnocentrismo ocidental, Jean e John Comarrot (Tradução de Iracema Dulley e Olívia, Janequine) escreveram o importante artigo Etnografia e imaginação histórica. In: Revista de Antropologia e Arte. IFICH-UNICAMP. Nele, ao indagarem sobre o lugar da Antropologia, os autores retomaram as obras de Evans-Pritchard (1937) e desconstruíram as ideias racialistas que atravessaram a segunda metade do XX, algumas permanecendo presentes até os dias de hoje. BARBUY, Heloisa. A exposição universal de 1889 em Paris: visão e representação na sociedade industrial. São Paulo: Edições Loyola, 1999.

Anos 90, Porto Alegre, v. 21, n. 40, p. 195-225, dez. 2014 


\section{Leila Maria Gonçalves Leite Hernandez}

${ }^{6}$ A obra de Gobineau foi parcialmente publicada em 1853 e na íntegra em 1855. Um artigo de inegável importância sobre esta obra é o de GAHYA, Helga da Cunha. "A epopeia da decadência": um estudo sobre "Essai sur l'inégalité des races humaines" (1853-1855), de Arthur de Gobineau. In: Mana, v. 17 n. 3, Rio de Janeiro, dezembro de 2011.

${ }^{7}$ JAMES, Cyril Lionel Robert. The Black Jacobins and the San Domingo Revolution teve uma primeira edição caribenha em 1938 e uma primeira tradução para o francês em 1949 (Gallimard, 1949); segunda edição em francês, em 1983 pela Ed. Amsterdam e uma reedição em 2008. No Brasil foi editado em São Paulo pela Boitempo, em 2000. A respeito do tema, vale destacar o artigo de Jacob Gorender O épico e o trágico na história do Haiti. In: Estudos Avançados. v. 18, n. 50. São Paulo. jan./abr. 2004.

${ }^{8}$ LOCKE, Alain. "The New Negro", The New Negro. (Org.). Alain Locke. New York: Atheneum, 1969 [1925], tradução de Manuela Ribeiro Sanches. Revisão de Maria José Rodrigues. In: SANCHES, Manuela Ribeiro (Org.). Malhas que os impérios tecem. (Lugar na História). Lisboa: Edições 70, 2011.

${ }^{9}$ DU BOIS, William Edward. Black Reconstruction: An Essay toward a History of the Part wich Black People Played in America, 1860-1880. New York: Russel and Russel, 1935; BLYDEN, Edward Wilmot. Christianity, Islam and Negro Race (1887). Reeditado pela Edinburgh University Press, 1967; GARVEY, Marcus Josiah. A Estrela Preta. Porto Alegre: Ed. Deriva, 2010. (Este livro é uma compilação de memórias, cartas e diários, provavelmente redigidos na década de 1930).

${ }^{10}$ CÉSAIRE, Aimé. Cabiers d'un Retour au Pays Natal, escrito entre 1936 e 1939 e sua segunda edição publicada pela editora Présence Africaine, em 1956. Quanto ao poema Orfeu Negro, é a Introdução à Anthologie de la Nowvelle Poésie Nègre et Malgache. Presses Universitaires, 1948.

${ }^{11}$ Présence Africaine, nos. 8-9-10, June-Nov. 1956. Neste exemplar estão as atas das sessões e dos textos apresentados no I Congresso Internacional dos Escritos e Artistas Negros, Paris, 1956.

${ }^{12}$ Estes artigos foram publicados na revista Présence Africaine, números 8-9-10, jun./nov. 1956, conforme assinalados na nota de número 2, onde estão as referências completas.

${ }^{13}$ SOUZA, Noémia de (2001). Sempre Negro. Maputo, s/e; NETO, Agostinho António (1985)... Ainda o meu sonbo... (Discursos sobre a cultura nacional) União dos Escritores Angolanos, e Discursos do Camarada Presidente Antonio Agostinho Neto (1985). Edição semestral (abril a setembro) Luanda: Gráfica Popular, UEE; CABRAL, Amílcar. Unité et Lute. (1980) (Organização de Mário Pinto de Andrade) Paris: Maspero; Nacionalismo y cultura (1999). Santiago de Compostela: Laiovento; ANDRADE, Mário Pinto de. (1997). Origens do nacionalismo africano: continuidade 


\section{A itinerância das ideias e o pensamento social africano}

e ruptura nos movimentos unitários emergentes da luta contra a dominação colonial portuguesa: 1911-1961. Lisboa: Dom Quixote. (Caminhos da Memória); BRAGANÇA, A.; DEPELCHIN, J. (1986) "Da Idealização da FRELIMO à Compreensão da História de Moçambique”. Estudos Moçambicanos n. 5/6, p. 29-52) In: MONDAINI, Marco (Org.). (2014). É preciso sonhar. Aquino de Bragança: independência e revolução na África portuguesa. Recife: Editora Universitária da UFPE, 2014 (Col. Clássicos, Série Brasil \& África).

${ }^{14}$ LOPES, Carlos. O Legado de Amílcar Cabral Diante dos Desafios da Ética Contemporânea. In: LOPES, Carlos (Org.). Desafios contemporâneos da África: O legado de Amílcar Cabral. São Paulo: UNESP, 2011. p. 185-204.

${ }^{15}$ BLYDEN, Edward Wilmot. Christianity, Islam and Negro Race. Edinburgh: Edinburgh University Press, 1967, reedição.

16 Tratei o papel das duas conferências em Elites Africanas, circulação de ideias e o nacionalismo anticolonial (2010). Quanto às Resoluções da Conferência de Bandung, foram citadas e alvo de pequena análise em Entre a concepção e a ação. (2005; 2008; 2010).

${ }^{17}$ Estas obras são as que estão referidas em nota anterior. Acrescente-se SARTRE, Jean-Paul. "Le Colonialisme est un Systeme”, Les Temps Modernes, n. 123, mar./abr. 1956. E também GRAMCSI, Antonio. Alguns temas da questão meridional, publicado pela primeira vez em 1930, em Paris, na revista Stato Operario, tratando da "revolução pelo alto" ou "revolução passiva" que subordina as "forças democráticas". Sobre os autores citados: COUTINHO, Carlos Nelson. De Rousseau a Gramsci. Ensaios de teoria política. São Paulo: Boitempo Editorial, 2011.

${ }^{18}$ SARTRE, Jean-Paul. L'Existencialisme est um Humanisme. Paris: Les edition Nagel, 1970. Na edição brasileira: O existencialismo é um humanismo. Seleção de textos de José Américo Peçanha. Tradução de Rita Guedes, Roberto Salinas e Bento Prado Júnior, 3. ed. São Paulo: Nova Cultural, 1987. Essas obras são as que estão referidas em nota anterior e acrescento SARTRE, Jean-Paul. "Le Colonialisme est um Systeme”, Les Temps Modernes, n. 1, 2, 3 mar./abr. de 1956. E também GRAMCSI, Antonio. Alguns temas da questão meridional, publicado pela primeira vez em 1930, em Paris, na revista Stato Operario, tratando da "revolução pelo alto" ou "revolução passiva" que subordina as "forças democráticas". Sobre os autores citados: COUTINHO, Carlos Nelson. De Rousseau a Gramsci. Ensaios de teoria política. São Paulo: Boitempo Editorial, 2011.

${ }^{19}$ A expressão é uma paráfrase da obra de Gilberto Freyre: $O$ mundo que o português criou, na qual o autor considera as sociedades colonizadas pelos portugueses como miscigenadas no âmbito de processos sem racismo, em que imperava a "democracia racial", mito central do tropicalismo dos anos de 1940. Uma interessantíssima leitura a respeito dessa obra é o livro de Claudia Castelo (1990), O modo português de estar no mundo.

Anos 90, Porto Alegre, v. 21, n. 40, p. 195-225, dez. 2014 


\section{Leila Maria Gonçalves Leite Hernandez}

\section{Referências}

ANDRADE, Mário Pinto de. (Coord.). Obras Escolbidas de Amilcar Cabral: unidade e luta. Lisboa: Seara Nova, 1976. 2 v.

APPIAH, Kwame Anthony. Na casa de men pai: a África na filosofia da cultura. Trad. Vera Ribeiro. Rio de Janeiro: Contraponto, 1997.

BALANDIER, Georges. A noção de situação colonial. Cadernos de campo: revista dos alunos da pós-graduação em Antropologia da Universidade de São Paulo, São Paulo, n. 3, 1993.

BARRY, Boubacar. Senegâmbia: o desafio da história regional. Rio de Janeiro: Centro de estudos Afro-Asiáticos, 2000.

BLYDEN, Edward Wilmot. Christianity, Islam and Negro Race. Edinburgh: Edinburgh University Press, 1967.

BOUFFON, George de. História Geral do Homem. Paris: M. Duchet, 1971, reedição. BRAGANÇA, A. \& DEPELCHIN, J. Da Idealização da FRELIMO à Compreensão da História de Moçambique. Estudos Moçambicanos. (n. 5/6, p. 29-52). In: MONDAINI, Marco (Org.). (2014). É preciso sonhar: Aquino de Bragança: independência e revolução na África portuguesa. Recife: Editora Universitária da UFPE, 1986. (Col. Clássicos, Série Brasil \& África).

CABRAL, Amílcar. Libertação Nacional e Cultura. Discurso proferido na Universidade de Syracuse, EUA, (Xerox), 1970.

. La Cultura: Fundamento Del Movimiento de Liberation. El Correo, UNESCO, ano XXVI, n. 11, 1973.

O papel da cultura na luta pela independência. In: Juventude e Cultura. Coimbra: Casa da Cultura da Juventude. n. 8. 1976, p. 14-15.

CASTELO, Cláudia. O modo português de estar no mundo. Porto: Afrontamento, 1999. CÉSAIRE, Aimé. Cabiers d'un Retour au Pays Natal. Paris: Editora Présence Africaine, 1956.

. Discurso sobre o colonialismo. Lisboa: Sá da Costa, 1978.

COUTINHO, Carlos Nelson. De Rousseau a Gramsci: Ensaios de teoria política. São Paulo: Boitempo Editorial, 2011.

CRUZ, Viriato Clemente. Poemas. Luanda: Nóssomos Ltda, 2013 


\section{A itinerância das ideias e o pensamento social africano}

DIOP, Cheik Anta. Nations Nègres et Culture: De l'Antiquité Nègre égiptienne aux problèmes culturels de l'Afrique d'aujoud'hui. Paris: Présence Africaine, 1954.

DU BOIS, William Edward. Black Reconstruction: An Essay toward a History of the Part wich Black People Played in America, 1860-1880. New York: Russel and Russel, 1935

FANON, Frantz. Os condenados da terra. Rio de Janeiro: Civilização Brasileira, 2. ed.1979

. Pele Negra Máscaras Brancas. Salvador: UFBA, 2009.

FIRMIN, Anténor N. De l'égalité des races bumaines (Antropologie positive). Paris: F. Pichon, Successeur, 1885.

FREYRE, Gilberto. O mundo que o português criou. Lisboa: Livros do Brasil, 1940. GARVEY, Marcus Josiah. A Estrela Preta. Porto Alegre: Ed. Deriva. (Este livro é uma compilação de memórias, cartas e diários, provavelmente redigidos na década de 1930), 2010.

GOBINEAU, Arthur de. Essai sur l'inegalité des races humaines. Paris:1853-1858. Reed: Paris: Pierre Belfond. 1985.

GORENDER, Jacob. O épico e o trágico na história do Haiti. In: Estudos Avançados. v. 18, n. 50. São Paulo. jan./abr. 2004.

HEGEL, Georg W. Friedrich. Phénomenologie de L'éspirit. Tome I. Trad. Jean Hyppolite. Paris: Aubier, 1939.

HERNANDEZ, Leila M. G. Leite. Elites Africanas, circulação de ideias e o nacionalismo anticolonial independentista. In: RIBEIRO A.; GEBARA A.; BITTENCOURT, M. (Org.). Africa, passado e presente: II Encontro de Estudos Africanos da UFF, 2010.

- A Africa na sala de aula: visita à história contemporânea. 4. ed. São Paulo: Ed. Selo Negro, 2012.

JAMES, Cyril Lionel Robert. The Black Jacobins: Toussaint L'ouverture and the San Domingo Revolution.

LARA, Lúcio. Imagens de um percurso. Associação Tchiweka de Documentação. Lisboa: Editorial Caminho, 2014.

LENIN, Vladimir. O Estado e a Revolução. São Paulo: Ed. Hucitec, 1987. . Imperialismo, fase superior do capitalismo. São Paulo: Global Editora, 1987.

LOCKE, Alain Leroy. The New Negro: An Interpretation. New York: Albert and Charles Boni, 1925. 


\section{Leila Maria Gonçalves Leite Hernandez}

LOPES, Carlos. O Legado de Amílcar Cabral Diante dos Desafios da Ética Contemporânea. In: LOPES, Carlos (Org.). Desafios contemporâneos da Affrica: O legado de Amílcar Cabral. São Paulo: UNESP, 2011. p. 185-204.

LUKÁCS, György. História e Consciência de Classe: Estudos sobre a dialética marxista. São Paulo: Martins Fontes, 2003.

MARX, Karl. Manuscritos Filosóficos de Agosto de 1844 ou Manuscritos de Paris, São Paulo: Boitempo, 2004.

MARX, K.; ENGELS, F. Manifesto do Partido Comunista. São Paulo: Ed. Escriba, 1968. MEMMI, Albert. Portrait du colonisé, précédé du Portrait du colonisateur. Paris: Payot, 1973. MONDAINI, Marco (Org.). É preciso sonhar: Aquino de Bragança: indivíduo e revolução na África portuguesa. Recife: Editora Universitária, 2004.

MONDLANE, E. Lutar por Moçambique. Maputo: CEA, 1995. Colecção "Nosso Chão.".

N'KRUMAH, Kwame. Neocolonialismo: último estágio do imperialismo. Rio de Janeiro: Civilização Brasileira, 1967.

PAZ, Octavio. Labirinto da solidão e Post Scriptum. Trad. de Eliane Zagury. Rio de Janeiro: Paz e Terra, 1984.

SAID, Edward. Reconsiderando a teoria itinerante. In: SANCHES, Manuela Ribeiro. (Org.). Deslocalizar a Europa: Antropologia, Arte, Literatura e História na Pós-colonialidade. Lisboa: Ed. Cotovia, 2005.

SARTRE, Jean-Paul. Le Colonialisme est un Systeme. Les Temps Modernes, n. 123, p. 1371-1386, mar./abr. 1956.

. Reflexões sobre o Racismo. I Reflexões sobre a Questão Judaica; II Orfeu Negro. São Paulo: DIFEL, 1960.

SENGHOR, Léopold Sédar. Orfeu Negro (Introdução à Anthologie de La nouvelle poésie Nègre et Malgache) In: SARTRE, Jean-Paul. Reflexões sobre o racismo. I Reflexões sobre a Questão Judaica; II Orfeu Negro. São Paulo: DIFEL, 1960. p. 105-149.

(Xerox), 1959.

- Relatório sobre a Doutrina e o Programa do Partido da Federação Africana.

Recebido em: 02/04/2014

Aprovado em: 22/09/2014

Anos 90, Porto Alegre, v. 21, n. 40, p. 195-225, dez. 2014 